\title{
Transboundary health impacts of transported global air pollution and international trade
}

Qiang Zhang ${ }^{1}$, Xujia Jiang ${ }^{1,2}$, Dan Tong ${ }^{1}$, Steven J. Davis ${ }^{3,1}$, Hongyan Zhao ${ }^{1}$, Guannan Geng ${ }^{1}$, Tong Feng ${ }^{1}$, Bo Zheng ${ }^{2}$, Zifeng Lu ${ }^{4}$, David G. Streets ${ }^{4}$, Ruijing Ni ${ }^{5}$, Michael Brauer ${ }^{6}$, Aaron van Donkelaar ${ }^{7}$, Randall V. Martin ${ }^{7}$, Hong Huo ${ }^{8}$, Zhu Liu ${ }^{9}$, Da Pan ${ }^{10}$, Haidong Kan ${ }^{11}$, Yingying Yan ${ }^{5}$, Jintai Lin ${ }^{5}$, Kebin $\mathrm{He}^{1,2,12}$, and Dabo Guan ${ }^{1,13}$

${ }^{1}$ Ministry of Education Key Laboratory for Earth System Modeling, Department of Earth System Science, Tsinghua University, Beijing 100084, People's Republic of China

${ }^{2}$ State Key Joint Laboratory of Environment Simulation and Pollution Control, School of Environment, Tsinghua University, Beijing 100084, People's Republic of China

${ }^{3}$ Department of Earth System Science, University of California, Irvine, California 92697, U.S.

${ }^{4}$ Energy Systems Division, Argonne National Laboratory, Argonne, IL 60439, U.S.

${ }^{5}$ Laboratory for Climate and Ocean-Atmosphere Studies, Department of Atmospheric and Oceanic Sciences, School of Physics, Peking University, Beijing 100871, People's Republic of China

${ }^{6}$ School of Population and Public Health, University of British Columbia, Vancouver, BC, V6T1Z3, Canada

${ }^{7}$ Department of Physics and Atmospheric Science, Dalhousie University, Halifax, NS, B3H4R2, Canada

${ }^{8}$ Institute of Energy, Environment, and Economy, Tsinghua University, Beijing 100084, People's Republic of China

${ }^{9}$ Resnick Sustainability Institute, California Institute of Technology, Pasadena, California 91125, U.S.

${ }^{10}$ Department of Civil and Environmental Engineering, Princeton University, Princeton, NJ 08544, U.S.

${ }^{11}$ School of Public Health, Key Lab of Public Health Safety of the Ministry of Education \& Key Lab of Health Technology Assessment of the Ministry of Health, Fudan University, Shanghai, People's Republic of China

${ }^{12}$ State Environmental Protection Key Laboratory of Sources and Control of Air Pollution Complex, Beijing 100084, People's Republic of China

${ }^{13}$ School of International Development, University of East Anglia, Norwich NR4 7TJ, UK 
Millions die prematurely every year from disease caused by exposure to outdoor air pollution $^{1-5}$. Some studies have estimated premature mortality related to local air pollution sources $^{6-7}$, but air quality and premature mortality can be affected by atmospheric transport of pollution from distant sources ${ }^{8-18}$. Moreover, international trade is contributing to the globalisation of emission and pollution as a result of the production of goods (and their associated emissions) in one region, for consumption in another region ${ }^{14,19-22}$. The effects of international trade on air pollutant emissions ${ }^{23}$, air quality $^{14}$, and health ${ }^{24}$ have been investigated regionally, but a combined, global assessment of the health impacts related to international trade and atmospheric air pollution transport is lacking. Here we link four global models to estimate premature mortality linked to fine particulate matter $\left(\mathbf{P M}_{2.5}\right)$ pollution as a result of atmospheric transport and the production and consumption of goods and services in different world regions. We find that, of $3.45(2.38-4.14,95 \% \mathrm{CI})$ million global premature deaths related to $\mathrm{PM}_{2.5}$ pollution in 2007 , about $12 \%$ or $411,100(352,800-469,300,95 \% \mathrm{CI})$ were related to air pollutants emitted in a different region of the world, and about $22 \%$ or $\mathbf{7 6 2 , 4 0 0}$ $(681,500-843,400,95 \% \mathrm{CI})$ were associated with goods and services produced in one region for consumption in another. For example, $\mathbf{P M}_{2.5}$ pollution produced in China in 2007 is linked to more than $64,800(44,400-85,100,95 \% \mathrm{CI})$ premature deaths in other regions, including over 3,100 $(1,800-4,200,95 \% \mathrm{CI})$ premature deaths in Western Europe and the U.S.; consumption in Western Europe and the U.S. is linked to over 108,600 $(64,300-153,000,95 \% \mathrm{CI})$ premature deaths in China. Our results reveal that inter-regional health impacts associated with $\mathbf{P M}_{2.5}$ pollution as a result of international trade are higher than those as a result of long-distance atmospheric pollutant transport.

Outdoor air pollution and its health impacts have typically been regarded as local or regional problems with similarly local or regional solutions. In response to the health risk caused by exposure to outdoor air pollution, many countries have adopted environmental laws regulating major sources of outdoor air pollution such as industry, agriculture, and transportation within their territories ${ }^{25}$. However, it is also increasingly recognized that air quality in a given location can be substantially affected by atmospheric transport of pollution from distant sources, including sources on other continents ${ }^{8-14}$. This pollution transport 
indicates that premature mortality related to air pollution is more than just a local issue ${ }^{12,15-18}$. Moreover, international trade is further globalizing the issue of air pollution mortality by separating the locations where goods are consumed from the locations where the emission and related pollution and mortality occur. Here, we link four state-of-the-art global models to estimate for the first time the premature mortality of global $\mathrm{PM}_{2.5}$ (fine particulate matter with diameter $\leq 2.5 \mu \mathrm{m}$ ) air pollution related to not only the pollution physically produced in different regions but also the pollution related to the goods and services that are ultimately consumed in each region. Only the premature mortality of $\mathrm{PM}_{2.5}$ pollution is estimated in our study given that prior studies have shown it accounts for over $90 \%$ of the global mortality from outdoor air pollution ${ }^{1,5}$.

Beginning with a newly developed emission inventory of primary air pollutants produced in 13 world regions in 2007 (Extended Data Fig. 1), we use a multi-regional input-output model of international trade to identify and isolate the emissions related to consumption and investment in each region in that year. A detailed documentation of the methodology and data used for developing the production- and consumption- based emission inventory is provided in Supplementary Information. We then track the fractions of globally distributed $\mathrm{PM}_{2.5}$ pollution contributed by emissions produced in each region and by emissions associated with each region's consumption, using the chemical transport model GEOS-Chem ${ }^{26}$. After that, we followed the methods of the Global Burden of Disease (GBD) Study ${ }^{1}$ to estimate the premature mortality due to ambient $\mathrm{PM}_{2.5}$ exposure related to each region's production and consumption, by applying the GEOS-Chem modeled regional fractional contributions to the mortality calculated from the GDB2013 high-resolution ambient $\mathrm{PM}_{2.5}$ concentrations ${ }^{27}$. $\mathrm{PM}_{2.5}$-related premature mortality linked to ischemic heart disease, stroke, lung cancer, and chronic obstructive pulmonary disease is calculated by using an integrated exposure model ${ }^{2}$ that estimate the risk of premature mortality from each of the four diseases at different $\mathrm{PM}_{2.5}$ exposure levels. Although errors propagated across multiple different global models may be large, we have conducted extensive uncertainty analyses and made careful comparisons to independent data ${ }^{12,13,18,27,28}$ in order to demonstrate the robustness of our main findings. A detailed description of these models, their integration, their uncertainty, comparisons with other studies, and a comprehensive listing of all data sources and key references is provided 
in Methods and Supplementary Information.

We estimate that $\mathrm{PM}_{2.5}$-related premature mortality in 2007 was 3.45 million (2.38-4.14 million, 95\%CI; Extended data Table 1; cf. 3.22 million deaths in 2010 reported by the GBD ${ }^{1}$ and 3.15 million in 2010 by Lelieveld et al. ${ }^{6}$ ). Of this total, we attribute 2.52 million deaths (1.74-3.02, 95\% CI) (attributable deaths, 73.0\%) to production activities in specific regions. The attributable production sectors include energy, industry, transportation, residential (both fossil fuels and biofuels), and agriculture. The remaining deaths are related to emissions from international shipping and aviation that are difficult to assign to specific regions, as well as natural sources such as biogenic emissions, field burning, forest fires, and mineral dust that are not directly related to consumption. Unless stated otherwise, the numbers of premature deaths reported below and in the figures thus correspond only to the attributable deaths and do not include those related to these unassigned emissions, and reflect median estimates rounded to the nearest hundred.

Figure 1a-d show the spatial distribution of premature deaths due to $\mathrm{PM}_{2.5}$ air pollution produced in China, Western Europe, the U.S., and India, respectively (see Extended Data Fig. 2a-i for analogous maps for other regions) in 2007. In each case, the largest health impacts of pollution produced in a given region are local, but deaths in neighboring regions as well as in more-distant areas are also evident due to intercontinental transport, particularly in downwind areas with dense populations. Our results are broadly consistent with previous transboundary studies $^{12,13,18}$, given the differences in various aspects of methodology (see details in Supplementary Information).

Figure 2a shows the share of deaths in each region due to emissions in other regions. As expected, hotspots of mortality impact from transboundary pollution occur in populous neighboring regions. For example, 30,900 (14,100-47,700, 95\%CI) deaths in the Rest of East Asia region (which includes Japan and South Korea) were related to emissions in China (Fig. 1a and 2a), and 47,300 (20,300-74,400, 95\% CI) deaths in Eastern Europe were related to emissions in Western Europe (Fig. 1c and 2a). More distant impacts also occur: 2,300 $(1,000-3,600,95 \% \mathrm{CI})$ deaths in Western Europe are related to pollution transported from the U.S. Globally, 16.3\% (13.3-19.3\%, 95\%CI) of attributable deaths (or 12.0\% (9.8-14.2\%, 95\% CI) of total deaths) were caused by pollution produced in a different region. 
In addition to the physical transport of pollution in the atmosphere, international trade has

a powerful influence on the location of health impacts by allowing the production of emissions to occur far from where goods and services are ultimately consumed. Figure 1 (right, e-h) shows the distribution of deaths due to $\mathrm{PM}_{2.5}$ pollution related to goods and services consumed in representative regions in 2007 (see Extended Data Fig. 3a-i for analogous maps for other regions). For each specific region, compared to the distribution of deaths caused by production of emissions, consumption-based deaths are scattered more widely around the world due to the impact of international trade (Fig. 1).

Figure $2 b$ presented the share of deaths in each region due to consumption in other regions. Regionally, the share of a region's deaths that are related to goods and services consumed elsewhere varies from as little as $15.2 \%(14.2-16.3 \%, 95 \% \mathrm{CI})$ in the case of more-isolated, less-developed regions like Sub-Saharan Africa to $53.7 \%(44.2-63.2 \%, 95 \% \mathrm{CI})$ in the case of energy exporting regions like Russia (Fig. 2b). The inter-region health impacts through international trade are much higher than through atmospheric transport. For example, $4.1 \%$ $(1.1-7.1 \%, 95 \% \mathrm{CI})$ of the total number of deaths in the U.S. are related to consumption in Western Europe, while only $0.2 \%(0.1-0.4 \%, 95 \% \mathrm{CI})$ of deaths in the U.S. are related to transboundary transport from Western Europe. Also noteworthy is the "spillover" effect in neighboring regions; $34.3 \%(19.9-48.7 \%, 95 \% \mathrm{CI})$ of deaths in the Rest of East Asia is attributable to the combined effects of pollution advection and international trade from China. Globally, $30.2 \%(25.4-35.0 \%, 95 \% \mathrm{CI})$ of the attributable deaths $(22.2 \%(18.7-25.7 \%, 95 \% \mathrm{CI})$ of total deaths) were caused by pollution that was produced in a different region from where the related goods and services were ultimately consumed.

International trade allows production and consumption activities to be physically separated, with emissions occurring within the region where the goods are produced and related health impacts concentrated within that producing region and nearby downwind regions, all of which may be far from the region where those goods are ultimately consumed. Figure 3 shows the net effect of international trade on emission, $\mathrm{PM}_{2.5}$ exposure, and mortality in each region, or the difference between each of these parameters when assigned to the location where goods and services were consumed rather than the location of production activities. Taking $\mathrm{SO}_{2}(\mathrm{a}$ key precursor of secondary $\mathrm{PM}_{2.5}$ ) as an example, Figure 3a shows the difference between 
where $\mathrm{SO}_{2}$ emissions were physically produced and where the related goods and services were consumed, or the emissions "embodied" in the net trade of goods and services among the 13 regions, in 2007. The world's most developed regions such as the U.S., Western Europe and Rest of East Asia are net embodied emission importers, which tend to import goods and services from China as well as their less-developed neighboring areas and caused pollution in the imported regions. China is the world's largest embodied emission exporter, with large quantities of $\mathrm{SO}_{2}$ embodied in exports to the above three regions.

In turn, emissions displaced via trade are transported in the atmosphere, which then affects population exposure to the pollution. Figure $3 b$ shows the difference in global, population-weighted mean concentrations of $\mathrm{PM}_{2.5}$ due to the emissions produced in each region and the emissions related to the goods and services consumed in each region, or $\mathrm{PM}_{2.5}$ exposure "embodied" in net trade. Although quite similar to the pattern of the emissions embodied in trade (i.e. Fig. 3a), these changes in air quality highlight cases where there are populous areas downwind of produced emissions. For example, emissions embodied in Chinese exports have a disproportionately large effect on exposure in population-dense regions (e.g., Japan and South Korea) that are near to and downwind of China (Fig. $3 b$ and Fig. 1).

Finally, Figure $3 \mathrm{c}$ shows the $\mathrm{PM}_{2.5}$-related premature mortality embodied in net trade, which incorporate the emissions displaced via trade, the subsequent changes in air quality as pollution is transported in the atmosphere, and the health impacts of poor air quality. Given China's population density, high emissions-intensity, large proportion of exports, and the large populations of neighboring regions, Chinese exports embody a greater number of deaths than exports from any other region (Fig. 3c). In contrast, net imports to the U.S. and Western Europe embody the greatest number of deaths (Fig. 3c).

Figure 4 summarizes the premature mortality due to both advection of $\mathrm{PM}_{2.5}$ air pollution and displacement of pollution via international trade with a series of bar charts. The per capita mortality is also presented in Extended Data Fig. 6 as an indicator of the emissions produced per person in a country and the relative health impacts of those emissions (see details in Methods section). Figure 4a shows that Chinese emissions cause more than twice the number of deaths worldwide than the emissions of any other region, followed by emissions produced 
in India and the Rest of Asia region. Perhaps surprisingly, Figure 4e shows that when these deaths are allocated according to where the related goods and services are consumed, China and India still dominate, which is consistent with the disproportionately local health impacts of air pollution. However, the roles of Western Europe and the U.S. are also highlighted by the consumption-based perspective (Fig. $4 \mathrm{a}$ and $4 \mathrm{e}$ ).

Figure $4 \mathrm{~d}$ shows the premature mortality in each region due to emissions produced in other regions, revealing the substantial health impacts of extraterritorial pollution in the Rest of Asia, India and Eastern Europe regions. When trade effects are also included, the transboundary health impacts increase drastically, particularly in China and other emerging markets (e.g., India and Russia), as well as in more-developed downwind regions, e.g. the Rest of East Asia region (including Japan and South Korea) (Fig. 4h). In turn, consumption in Western Europe, the U.S. and the Rest of Asia region correspond to the greatest number of deaths in other regions (Fig. $4 \mathrm{~g}$ ).

Our findings quantify the extent to which air pollution is a global problem. In our global economy, the goods and services consumed in one region may entail production of large quantities of air pollution — and related mortality —in other regions. If the cost of imported products is lower because of less stringent air pollution controls in the regions where they are produced, then the consumer savings may come at the expense of lives lost elsewhere ${ }^{29-30}$. Regional policies that regulate air quality by imposing a price on pollutant emissions may be effective, and in some cases a considerable proportion of the overall costs of such policies might be shared with consumers in other regions ( $c f$. Fig. 3a). However, there is some evidence that the polluting industries have tended to migrate to regions with more permissive environmental regulations ${ }^{29-30}$, suggesting that there may be tension between a given region's efforts to improve air quality and attract foreign direct investment. Improving pollution control technologies in China, India and elsewhere in Asia would have a disproportionately large health benefit in those regions and worldwide, and international cooperation to support such pollution abatement efforts and reduce "leakage" of emission via international trade is in the global interest. 


\section{References}

1 Lim, S. S. et al. A comparative risk assessment of burden of disease and injury attributable to 67 risk factors and risk factor clusters in 21 regions, 1990-2010: a systematic analysis for the global burden of disease study 2010. The Lancet 380, 2224-2260 (2012).

2 Burnett, R. T. et al. An integrated risk function for estimating the global burden of disease attributable to ambient fine particulate matter exposure. Environ. Health Perspect. 122, 397-403 (2014).

3 Pope, C. A. et al. Lung cancer, cardiopulmonary mortality and long-term exposure to fine particles air pollution. J. Am. Med. Assoc. 287, 1132-1141 (2002).

4 Cohen, A. J. et al. The global burden of disease due to outdoor air pollution. J. Toxicol. Environ. Health A 68, 1301-1307 (2005).

5 Forouzanfar, M. H., Alexander, L., Anderson, H. R., Bachman, V. F. \& Biryukov, S. Global, regional, and national comparative risk assessment of 79 behavioural, environmental and occupational, and metabolic risks or clusters of risks in 188 countries, 1990-2013: a systematic analysis for the Global Burden of Disease Study 2013. The Lancet 386, 2287-2323 (2015).

6 Lelieveld, J., Evans, J. S., Fnais, M., Giannadaki, D. \& Pozzer, A. The contribution of outdoor air pollution sources to premature mortality on a global scale. Nature 525, 367-371 (2015).

7 Chafe, Z. A. et al. Household cooking with solid fuels contributes to ambient $\mathrm{PM}_{2.5}$ air pollution and the burden of disease. Environ. Health Perspect. 122, 1314-1320 (2014).

8 Akimoto, H. Global air quality and pollution. Science 302, 1716-1719 (2003).

9 Jaffe, D. et al. Transport of Asian air pollution to North America. Geophys. Res. Lett. 26, 711-714 (1999).

10 Cooper, O. R. et al. A case study of transpacific warm conveyor belt transport: Influence of merging airstreams on trace gas import to North America. J. Geophys. Res. 109, D23S08 (2004).

11 Verstraeten, W. W. et al. Rapid increases in tropospheric ozone production and export from China. Nature Geosci. 8, 690-695 (2015).

12 Liu, J., Mauzerall, D. L. \& Horowitz, L. W. Evaluating inter-continental transport of fine aerosols: (2) Global health impact. Atmos. Environ. 43, 4339-4347 (2009).

13 HTAP, UNECE. Hemispheric Transport of Air Pollution 2010: Part A: Ozone and Particulate Matter, Air Pollution Studies No. 17, edited by: Dentener, F., Keating, T., and Akimoto, H., ECE/EN.Air/100, ISSN 1014-4625, ISBN 978-92-1-117043-6 (2010).

14 Lin, J. et al. China's international trade and air pollution in the United States. Proc. Natl. Acad. Sci. U.S. 111, 1736-1741 (2014).

15 Duncan, B. N., West, J. J., Yoshida, Y., Fiore, A. M. \& Ziemke, J. R. The influence of European pollution on ozone in the Near East and northern Africa. Atmos. Chem. Phys. 8, 2267-2283 (2008).

16 West, J. J., Naik, V., Horowitz, L. W. \& Fiore, A. M. Effect of regional precursor emission controls 
on long-range ozone transport - Part 2: Steady-state changes in ozone air quality and impacts on human mortality. Atmos. Chem. Phys. 9, 6095-6107 (2009).

17 Anenberg, S. C. et al. Intercontinental Impacts of Ozone Pollution on Human Mortality. Environ. Sci. Technol. 43, 6482-6487 (2009).

18 Anenberg, S. C. et al. Impacts of intercontinental transport of anthropogenic fine particulate matter on human mortality. Air Qual Atmos Health 7, 369-379 (2014).

19 Davis, S. J. \& Caldeira, K. Consumption-based accounting of $\mathrm{CO}_{2}$ emissions. Proc. Natl. Acad. Sci. U.S. 107, 5687-5692 (2010).

20 Peters, G. P., Minx, J. C., Weber, C. L. \& Edenhofer, O. Growth in emission transfers via international trade from 1990 to 2008. Proc. Natl. Acad. Sci. U.S. 108, 8903-8908 (2011).

21 Liu, J. et al. Systems integration for global sustainability. Science 347 (2015).

22 Oita, A. et al. Substantial nitrogen pollution embedded in international trade. Nature Geosci. 9, 111-115 (2016)

23 Zhao, H. et al. Assessment of China's virtual air pollution transport embodied in trade by a consumption-based emission inventory. Atmos. Chem. Phys. 15, 5443-5456 (2015).

24 Jiang, X. et al. Revealing the hidden health costs embodied in Chinese exports. Environ. Sci. Technol. 49, 4381-4388 (2015).

25 Zhang, Q., He, K. \& Huo, H. Cleaning China's air. Nature 484, 161-162 (2012).

26 Bey, I. et al. Global modeling of tropospheric chemistry with assimilated meteorology: Model description and evaluation. J. Geophys. Res. 106, 23073-23096 (2001).

27 Brauer, M. et al. Ambient air pollution exposure estimation for the global burden of disease 2013. Environ. Sci. Technol. 50, 79-88 (2016).

28 Janssens-Maenhout, G. et al. HTAP_v2.2: a mosaic of regional and global emission grid maps for 2008 and 2010 to study hemispheric transport of air pollution. Atmos. Chem. Phys. 15, 11411-11432 (2015).

29 Levinson, A. \& Taylor, M. S. Unmasking the pollution haven effect. Int. Econ. Rev. 49, 223-254 (2008).

30 Kanemoto, K., Moran, D., Lenzen, M. \& Geschke, A. International trade undermines national emission reduction targets: New evidence from air pollution. Glob. Environ. Chang. 24, 52-59 (2014).

\section{Figure legends}

Figure 1 | Worldwide premature mortality due to $\mathbf{P M}_{2.5}$ air pollution. Maps show the number of deaths related to either the air pollution produced (i.e. emitted) in (a-d) or pollution related to goods and services consumed in (e-h) China, Western Europe, the U.S. and India. Differences of worldwide premature mortality between production- and consumption-based $\mathrm{PM}_{2.5}$ air pollution for these four 
regions are presented in Extended Data Fig. 4.

Figure 2 | Shares of $\mathbf{P M}_{2.5}$-related deaths in each region related to emissions produced or goods and services consumed in other regions. Each cell in the grid shows the fraction of deaths (\%) that occurred in the column region due to pollution produced in the row region (a) or goods and services consumed in the row region (b). The diagonal thus reflects deaths in a region due to pollution produced (a) or goods and services consumed (b) in that same region. In each case, total deaths in each region are shown at the top, and the worldwide deaths caused by pollution produced (a) or consumption (b) in each region are shown at the right. Uncertainty ranges of numbers in this figure are presented in Extended Data Fig. 5.

Figure 3 | Emissions, air quality changes, and premature mortality embodied in trade. Maps show differences between production- and consumption-based accounting of $\mathrm{SO}_{2}$ emissions (a; $\mathrm{Mt} \mathrm{SO}_{2} / \mathrm{yr}$ ), population-weighted average $\mathrm{PM}_{2.5}$ exposure $\left(\mathbf{b} ; \mu \mathrm{g} / \mathrm{m}^{3} \mathrm{PM}_{2.5}\right.$ ), and premature mortality due to $\mathrm{PM}_{2.5}$ air pollution (c; deaths). In each case, net importers are shown in red colors and net exporters in blue colors. Although the emissions embodied in exports from regions like Latin America, Canada, Sub-Saharan Africa and Australia are greater than the emissions embodied in their imports (blue shading in a), the $\mathrm{PM}_{2.5}$ exposure and mortality embodied in imports to those regions are greater than exposure and mortality embodied in their exports (red shading in $\mathbf{b}$ and $\mathbf{c}$ ). The differences are due to differences in population density (b) and marginal health impacts of emissions (c) in regions like China, Europe, India and the Rest of Asia region (i.e. Central and Southeast Asia) which are the source of many of the goods imported by other regions. The U.S., Western Europe, and the Rest of East Asia region (South Korea and Japan) are net importers of pollution, exposure and deaths. Note that Mongolia, North and South Korea and Japan are grouped in a single region (Rest of East Asia), which tends to overemphasize the effect of trade in Mongolia in particular.

Figure 4 | Summary of global premature mortality due to transported $\mathbf{P M}_{2.5}$ pollution and traded products. Worldwide mortality due to pollution produced (i.e. emitted) in each region (a), worldwide mortality related to products consumed in each region (e), mortality in region due to pollution produced in that region (b), mortality in region related to products consumed in that region (f), mortality in other regions due to pollution produced in each region (c), mortality in other regions related to products consumed in each region (g), mortality in each region due to pollution produced elsewhere (d), and mortality in each region related to products consumed elsewhere (h). Error bars in each panel presented uncertainty ranges $(95 \% \mathrm{CI})$ of the estimates, which are determined by uncertainties in GEOS-Chem simulated fractional contribution of $\mathrm{PM}_{2.5}$ exposure and in total $\mathrm{PM}_{2.5}$ related mortality. 
Innovation Center for Regional Environmental Quality. The work at Argonne National Laboratory acknowledges the Modeling, Analysis and Predictability (MAP) program of the National Aeronautics and Space Administration (NASA) under Proposal No. 08-MAP-0143, for which we thank David Considine (NASA) and Mian Chin (NASA Goddard Space Flight Center). H.H. acknowledges the support of the National Natural Science Foundation of China (71322304). We thank Dr. Tao Xue for helpful discussions on statistics.

Author Contributions Q.Z., J.L., and K.H. conceived the study. Q.Z. led the study. Z.Lu and D.G.S. provided emission data. M.B., A.V.D., and R.V.M. provided PM 2.5 exposure data. D.T., H.Z., T.F., and D.G. calculated emissions. G.G. conducted GEOS-Chem simulations. X.J. conducted health impacts estimates. Q.Z., X.J., S.J.D., G.G., and J.L. interpreted the data. Q.Z, X.J., D.T., S.J.D., H.Z., and G.G. wrote the paper with inputs from all co-authors.

Author Information Q.Z., X.J., and D.T contributed equally to this work. Reprints and permissions information is available at www.nature.com/reprints. The authors declare no competing financial interests. Readers are welcome to comment on the online version of the paper. Correspondence and requests for materials should be addressed to Q.Z. (qiangzhang@tsinghua.edu.cn), S.J.D. (jdavis@uci.edu), J.L. (linjt@pku.edu.cn), or K.H. (hekb@tsinghua.edu.cn).

\section{Methods}

\section{Integrated model framework}

This study required integration of data, models and methods from multiple sources and scientific disciplines, as depicted in Extended Data Fig. 7. We first developed a global inventory of all major sources of anthropogenic air pollution emissions in 228 countries and regions for the year 2007, disaggregating emissions from 62 sub-sectors (as opposed to aggregated sectors in available global inventories). We then used a global multi-regional input-output model (MRIO) ${ }^{31,32}$ based on data from the Global Trade Analysis Project $(\text { GTAP })^{33}$ to re-attribute the emissions produced by these different sectors according to the demand of consumers for finished goods. The MRIO thus traces all emissions related to consumed goods back to the original sources of produced emissions, even if the supply chain of the consumed products encompasses intermediate inputs (e.g., parts) and services (e.g., assembly and transport) from multiple sectors across multiple regions. Prior to the re-attribution, the production-based global emission inventory was mapped to 129 regions and 57 sectors in GTAP to facilitate the MRIO analysis. Next, we used the GEOS-Chem chemical transport model $^{26}$ to track physical transport of emissions in the atmosphere, obtaining each region's fractional contribution to global near-surface $\mathrm{PM}_{2.5}$ concentrations from both production and consumption perspectives by a zero-out approach. These derived ratios were 
further multiplied by high-resolution global $\mathrm{PM}_{2.5}$ concentration data ${ }^{27}$ developed for the Global Burden of Disease Study of 2013 (GBD2013) to get the $\mathrm{PM}_{2.5}$ exposure levels from both production and consumption perspectives. Given computational constraints, the GEOS-Chem modeling required further geographical aggregation: we classified the world into 13 regions based on their level of economic development, regions in the trade model, and levels of air pollution: China, Rest of East Asia, India, Rest of Asia, Russia, Western Europe, Eastern Europe, Middle East and North Africa, the U.S, Canada, Latin America, Sub-Saharan Africa, and Rest of World. The detailed classifications from 228 countries sorted into these 13 regions are shown in Supplementary Table 1 and Extended Data Fig. 1. Finally, we applied the Integrated Exposure-Response (IER) model $^{2}$ to evaluate the effect of changes in $\mathrm{PM}_{2.5}$ concentrations to premature mortality, summing across regions to obtain the global $\mathrm{PM}_{2.5}$ mortality related to both emissions produced and goods consumed in each region. Detailed information of all above steps is presented in the Supplementary Information.

We conducted comprehensive uncertainty analyses integrating errors in all steps, and compared our results with independent data. In summary, we estimate uncertainty $(\mathrm{p}=0.005)$ associated with production-based emissions using distributions of key parameters derived from the literature, expert judgments and measurement data for each industrial subsector in each of the 13 regions. Our estimates are generally consistent with the HTAP v2.2 emission inventory ${ }^{28}$ that represents the state-of-the-art understanding of global emissions. We also evaluate uncertainty related to our modeling of atmospheric transport (including, e.g., sensitivity analyses of nonlinear effects and neglected NMVOC emissions), and compare our results to both ground-based observations and GBD $\mathrm{PM}_{2.5}$ concentrations. Our results on transboundary transport of $\mathrm{PM}_{2.5}$ are generally consistent with the HTAP study ${ }^{13}$ when harmonizing the model domain and target species. And we assess uncertainties of our mortality estimates by varying the applicable parameters in our Integrated Exposure-Response model across 1,000 trials and our estimates of mortality are very close to the $\mathrm{GBD}^{1}$ and Lelieveld et al. ${ }^{6}$. Details of these analyses are presented in the Supplementary Information.

\section{Per capita mortality due to transported pollution and traded products}

Extended Data Figure 6a shows that the emissions produced by a million Eastern Europeans result in 1,027 (749-1,306, 95\%CI) $\mathrm{PM}_{2.5}$-related deaths around the world, a greater impact per capita than any other region. Having the world's largest population, per capita impacts in China are quite substantial: the emissions produced per million Chinese cause 770 (529-1,014, 95\%CI) deaths worldwide (Extended Data Fig. 6a). In terms of consumption, individuals in the affluent regions, e.g., Western Europe, the U.S., and Canada, are related to greater than average number of deaths worldwide (Extended Data Fig. 6e). Further, a disproportionate number of those deaths occurred in other regions; every million Western European, Canadian and U.S. consumers were tied to 416 (303-530, 95\%CI), 395 
(268-522, 95\%CI), and $339(231-448,95 \% \mathrm{CI})$ deaths in other regions, respectively (Extended Data Fig. 6g). Per capita, Eastern Europe and Russia suffered more of these transboundary deaths than any other regions: per million people in those regions, 531 (335-727, 95\%CI) and $365(278-453,95 \% \mathrm{CI})$ died, respectively, due to products consumed elsewhere (Extended Data Fig. 6h).

\section{References}

31 Peters, G. P., Andrew, R. \& Lennox, J. Constructing an environmentally-extended multi-regional Input-output table using the GTAP database. Econ. Syst. Res. 23, 131-152 (2011).

32 Andrew, R. M. \& Peters, G. P. A multi-region input-output table based on the global trade analysis project database (GTAP-MRIO) Econ. Syst. Res. 25, 99-121 (2013).

33 Badri, N., Angel, A. \& Robert, M. Global Trade, Assistance, and Production: The GTAP 8 Data Base. (Center for Global Trade Analysis, Purdue University, 2012).

Data availability statement The datasets generated during the current study are available from the corresponding author on reasonable request.

\section{Extended Data Legends}

Extended Data Figure 1 | Definition of 13 world regions in this study.

Extended Data Figure 2 | Global distribution of premature mortality related to production-based PM2.5 air pollution. Maps show the number of deaths related to air pollution produced (i.e., emitted) in (a) Rest of East Asia, (b) Rest of Asia, (c) Russia, (d) Eastern Europe, (e) Canada, (f) Middle East and North Africa, (g) Latin America, (h) Sub-Saharan Africa, and (i) Rest of the world.

\section{Extended Data Figure 3 | Global distribution of premature mortality related to} consumption-based PM2.5 air pollution. Maps show the number of deaths related to goods and services consumed in (a) Rest of East Asia, (b) Rest of Asia, (c) Russia, (d) Eastern Europe, (e) Canada, (f) Middle East and North Africa, (g) Latin America, (h) Sub-Saharan Africa, and (i) Rest of the world.

Extended Data Figure 4 | Differences of worldwide premature mortality between production- and consumption-based $\mathbf{P M}_{2.5}$ air pollution (consumption-based minus production-based).

\section{Extended Data Figure 5 | Uncertainty ranges of Figure 2. The top and the right represent the 95\%}

CI ranges of total number of death. Each cell in the grid shows the standard derivation of the fraction of deaths $(\%)$

\section{Extended Data Figure 6 | Summary of global premature mortality per capita of population due to}


transported pollution and traded products. Worldwide mortality due to pollution produced (i.e. emitted) in each region (a), worldwide mortality related to products consumed in each region (e), mortality in region due to pollution produced in that region (b), mortality in region related to products consumed in that region (f), mortality in other regions due to pollution produced in each region (c), deaths in other regions related to products consumed in each region $(\mathrm{g})$, mortality in each region due to pollution produced elsewhere (d), and mortality in each region related to products consumed elsewhere (h). Data are normalized according to regional population.

Extended Data Figure 7 | Methodology framework to access PM2.5 mortality from each region' production and consumption.

448

Extended Data Table 1 | Premature mortality related to $\mathrm{PM}_{2.5}$ air pollution in 2007. 